\title{
Severe airway obstruction in an infant with congenital tracheal stenosis and congenital heart disease -A case report-
}

\author{
Eun Soo Kim, Ji-Young Yoon, Tae Kyun Kim, Jung-Min Hong, and Jae Eun Kim \\ Department of Anesthesia and Pain Medicine, School of Medicine, Pusan National University Hospital, Busan, Korea
}

Congenital tracheal stenosis (CTS), though rare, is important because the mortality and morbidity rates are high in infants. Especially, associated congenital heart disease (CHD) in these infants may compound the effects of airway pathology. A 3-week-old patient with long-segmental tracheal stenosis below an anomalous right-upper lobe (RUL) bronchus had undergone a total correction of double outlet right ventricle. On third postoperative day, hypercarbia developed, and severe airway obstruction and atelectasis were detected. An emergency slide tracheoplasty was performed under cardiopulmonary bypass (CPB). The patient recovered well after the surgery. Thus, special attention needs to be paid during the postoperative intensive care of patients with congenital tracheal anomalies. Early detection and prompt diagnosis of airway obstruction can help reduce the morbidity and mortality rates. Further, it is important to select the suitable treatment of CTS associated with CHD. (Korean J Anesthesiol 2012; 62: 285-288)

Key Words: Airway obstruction, Congenital, Heart disease, Tracheal stenosis.

Congenital tracheal stenosis (CTS) is a rare, but life-threatening condition and the mortality rate is $44-79 \%$ [1]. Airway obstruction in patient with CTS could be exacerbated due to spasms, inflammation, or direct trauma after airway manipulation or surgery [2]. In several studies, CTS is associated with other congenital anomalies, especially congenital heart disease (CHD) and tracheal bronchus [3,4]. In infants with congenital tracheobronchial anomalies accompanying CHD, the risk of severe airway obstruction may increase in the perioperative period because of invasive access to the upper airways during intubation and airway manipulation, cardiopulmonary bypass (CPB), or prolonged mechanical ventilation [5]. Associated tracheal bronchus also increases the risk of respiratory complications after endotracheal tube (ETT) intubation [6].

We present a case of CTS combined with CHD and tracheal bronchus to create awareness among clinicians that such a condition could result in severe airway obstruction and prolonged atelectasis in perioperative period.

Received: March 17, 2011. Revised: 1st, May 3, 2011; 2nd, May 9, 2011. Accepted: May 9, 2011.

Corresponding author: Ji-Young Yoon, M.D., Department of Anesthesia and Pain Medicine, School of Medicine, Pusan National University, 1-10, Ami-dong, Seo-gu, Busan 602-739, Korea. Tel: 82-51-240-7391, Fax: 82-51-242-7466, E-mail: dryoonji@pusan.ac.kr (c) This is an open-access article distributed under the terms of the Creative Commons Attribution Non-Commercial License (http:// creativecommons.org/licenses/by-nc/3.0/), which permits unrestricted non-commercial use, distribution, and reproduction in any medium, provided the original work is properly cited. 


\section{Case Report}

A 3-week-old female patient weighing 3,180 g, was scheduled for total correction of double outlet right ventricle (DORV) with CPB. She was born at the gestational age of 41 weeks from a healthy mother after a normal pregnancy and vaginal delivery; her weight at the time of delivery was $2,800 \mathrm{~g}$. She was hospitalized because of pneumonia of the right upperlobe (RUL). A heart murmur was detected during a physical examination incidentally. Echocardiography revealed a large perimembranous ventricular septal defect (VSD) with overriding aorta. She was, therefore, referred to our hospital for surgery. During preoperative evaluation, 3-dimensional reconstruction computed tomography (CT) of the thorax revealed stenosis of the trachea and tracheal bronchus (Fig. 1). A tracheal bronchus, with no upper lobe bronchi arising from the right main bronchus, had arisen from the right wall of the trachea $20 \mathrm{~mm}$ below the vocal cord. The stenotic lesion had extended from the origin of tracheal bronchus to the carina (length of stenosis was $22 \mathrm{~mm}$ ), without involving the carina. The luminal diameter at the narrowest of the trachea was $2.4 \mathrm{~mm}$. Although the patient presented with recurrent pneumonia, surgical intervention for tracheal stenosis was not scheduled because her respiratory condition was not compromised by the stenosis. Laboratory investigation revealed no significant findings.

Anesthesia was induced with thiopental sodium $(5 \mathrm{mg} / \mathrm{kg}$ body weight), fentanyl ( $3 \mu \mathrm{g} / \mathrm{kg}$ body weight), and rocuronium ( $0.6 \mathrm{mg} / \mathrm{kg}$ body weight). A $3.5 \mathrm{~mm}$ uncuffed ETT was placed $5 \mathrm{~mm}$ above the tracheal bronchus, and the accuracy of tube positioning was confirmed by using a fiberoptic bronchoscope

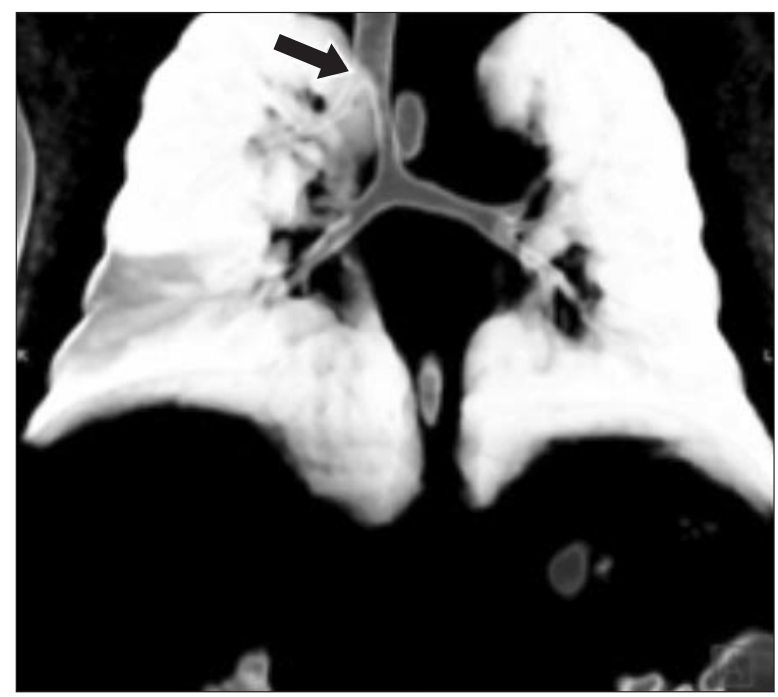

Fig. 1. Three-dimensional reconstruction CT preoperatively showing long segmental stenosis below an anomalous right upper lobe tracheal bronchus (arrow).
(BF-N20; Olympus, Tokyo, Japan). General anesthesia was maintained with sevoflurane (end-tidal concentration of 1.0$2.0 \%)$ and intravenous infusion of fentanyl $(3-5 \mu \mathrm{g} / \mathrm{kg} / \mathrm{h})$, and intermittent bolus doses of rocuronium $(0.15 \mathrm{mg} / \mathrm{kg}$ body weight). Mechanical ventilation was performed in a pressurecontrolled mode with peak inspiratory pressure (PIP), 18-20 $\mathrm{cmH}_{2} \mathrm{O}$; respiratory rate (RR), 20-25 breaths/min; end-tidal carbon dioxide $\left(\mathrm{ETCO}_{2}\right), 30-40 \mathrm{mmHg}$; fraction of inspired oxygen $\left(\mathrm{FiO}_{2}\right), 0.5-1.0$, with oxygen saturation $\left(\mathrm{SpO}_{2}\right)$ ranging from $99-100 \%$. The total correction of DORV was performed uneventfully under CPB. The CPB time was 81 minutes and the operation took 195 minutes.

The patient was transferred to the intensive care unit (ICU). She was put on pressure-controlled ventilation under the following conditions: PIP, $20-23 \mathrm{cmH}_{2} \mathrm{O}$; RR, 20-25 breaths/ min; positive end-expiratory pressure, 3-5 $\mathrm{cmH}_{2} \mathrm{O} ; \mathrm{ETCO}_{2}$, 32-55 mmHg; $\mathrm{FiO}_{2}, 0.4-0.8 ; \mathrm{SpO}_{2}$ 98-99\%. The immediate postoperative course was uneventful. On the first postoperative day (POD), spontaneous breathing trial was performed to discontinuation on mechanical ventilation and early postoperative extubation using T-piece. Significant hypercarbia $\left(\mathrm{PaCO}_{2}\right.$ was 60-70 $\mathrm{mmHg}$ ) and tachypnea (RR was $55-60$ breaths/min) persisted and the tracheal tube could not be removed. Despite adjustments to increase minute ventilation, there was a gradual increase in end tidal carbon dioxide by $60-70 \mathrm{mmHg}$ on POD $\# 2-3$. PIP in a pressure-controlled mode was readjusted from 20-23 $\mathrm{cmH}_{2} \mathrm{O}$ to $28-33 \mathrm{cmH}_{2} \mathrm{O}$. An arterial blood gas analysis showed pH 7.16; $\mathrm{PaCO}_{2}, 89 \mathrm{mmHg} ; \mathrm{PaO}_{2}, 124 \mathrm{mmHg}$; and $\mathrm{SpO}_{2}$, $98 \%\left(\mathrm{FiO}_{2}\right.$ 0.8). Chest auscultation revealed reduced breath sounds bilaterally. Plain chest radiography indicated RUL

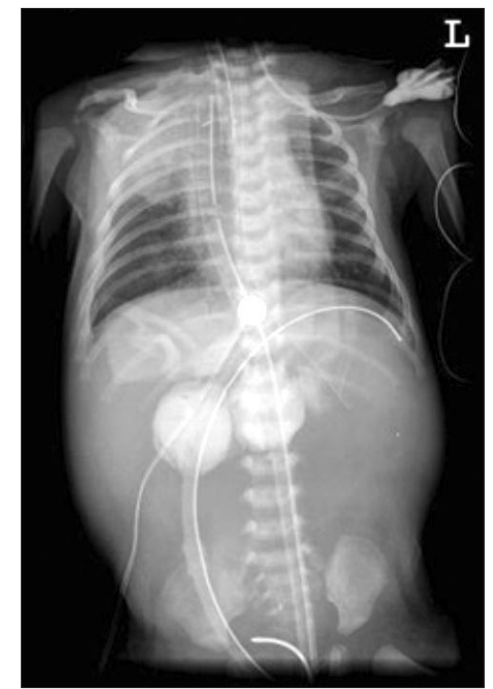

Fig. 2. Chest X-ray on postoperative day 2 revealing right upper lobe atelectasis. 
atelectasis (Fig. 2). Fiberoptic bronchoscopy revealed almost complete occlusion of trachea below the tracheal bronchus. The patient was scheduled for surgical repair of congenital tracheal stenosis under slide tracheoplasty using CPB.

The findings of the preoperative arterial blood gas analysis were as follows: $\mathrm{pH}$ 7.01; $\mathrm{PaCO}_{2}, 115 \mathrm{mmHg}$; $\mathrm{PaO}_{2}, 76 \mathrm{mmHg}$; and $\mathrm{SpO}_{2}, 93 \%\left(\mathrm{FiO}_{2}\right.$ 0.8). Other laboratory investigations revealed no significant findings. Immediately after the induction of general anesthesia, the patient's condition deteriorated rapidly and ventilation was not effective. Arterial blood gas analysis revealed severe respiratory acidosis with $\mathrm{CO}_{2}$ retention of up to $130 \mathrm{mmHg}$. A median sternotomy was reopened promptly to expose the heart and blood vessels. After the establishment of $\mathrm{CPB}, \mathrm{CO}_{2}$ levels were gradually reduced during the bypass period. The ETT was removed and fiberopic bronchoscopy was performed to confirm the extent and degree of stenosis. The trachea was then transected at the narrowest point which inner diameter was $1.0 \mathrm{~mm}$ (Fig. 3). Slide tracheoplasty was performed without any complications. Following this, the ETT was repositioned under direct visual guidance and mechanical ventilation was then resumed and $\mathrm{CPB}$ withdrawn. At the end of the surgery, the patient was hemodynamically stable.

The patient was transferred to the ICU and placed under pressure controlled ventilation support. On POD \#4, a portable chest X-ray showed an improvement in the RUL atelectasis. The endotracheal tube was extubated on POD \#7 successfully. She was discharged from the ICU on POD \#9. Three-dimensional reconstruction CT on POD \#11 demonstrated an almost normal trachea and mild stenosis of the proximal main bronchus, but she did not suffer from any respiratory symptom.

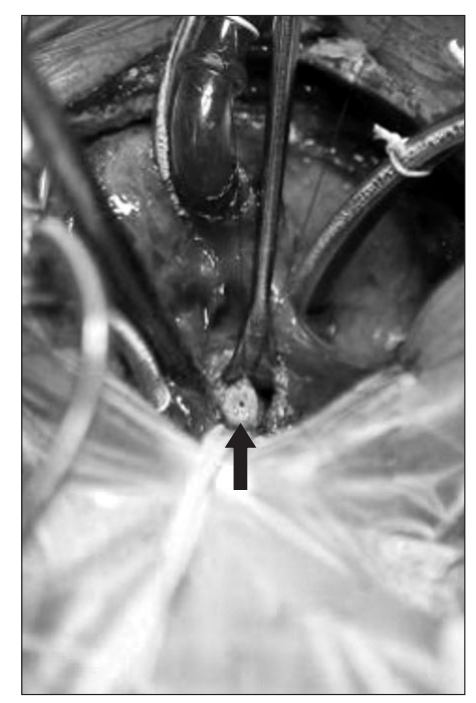

Fig. 3. Surgical field photography showing a narrowest portion of the trachea. The trachea (arrow) was near totally occluded by mucosal swelling.

\section{Discussion}

CTS is a life-threatening, emergency condition that usually presents very early in life and causes severe respiratory distress. It is a rare anomaly in the general population, but the incidence of CTS in infant with CHD has been reported to be $2.5 \%[3,7]$. A study of multicenter analysis reported that the highest mortality rate was observed in CTS patients younger than 1 month and in those with CHD [8]. Prompt diagnostic evaluation of the airway should be performed in infants with symptoms, such as stridor, episodic desaturation, failure of postoperative extubation, neonatal respiratory distress. Flexible bronchoscopic assessment is safe and useful for evaluation of airway problems complicating congenital heart disease perioperatively [9]. Recently, 3-dimensional reconstruction CT has been recommended for routine evaluation of tracheobronchial anomalies in patient with CHD [4].

The optimal treatment for CTS remains controversial, ranging from conservative therapy to surgical intervention. Conservative management is preferred in infant with mild symptoms as an initial approach. Depending on the size and location of the obstruction, surgical approaches like resection-anastomosis or various forms of tracheoplasty may be considered. Recent studies reported that slide tracheoplasty was a preferred method for long-segmental stenosis [10,11]. And several studies demonstrated that simultaneous repair of CTS and cardiac anomalies is a reasonable surgical approach [12,13]. But staged correction may be considered in infants with long-segment CTS and complex cardiac anomalies because those still remain difficult to treat [5].

Tracheal bronchus is a relatively common airway anomaly. The incidence of tracheal bronchus is approximately $2 \%$ [6]. Tracheal bronchus may be asymptomatic or may result in recurrent infections due to the retention of secretions. An anomalous RUL bronchus originating from the trachea, at the level of or above the carina, also increases the risk of complications following ETT intubation. If the ETT insertion is very deep, the retention of secretions and obstruction of the tracheal bronchus by the ETT can contribute to RUL atelectasis. Similar problems have been reported in patients with tracheal bronchus undergoing intubation for anesthesia [14,15].

In our case, congenital tracheal anomalies accompanying CHD resulted in severe airway obstruction and atelectasis during postoperative intensive care. The patient's airway, being very small in diameter, was most vulnerable to further stenosis in the event of a careless minor injury. Airway manipulation, mucosal edema, and inflammation associated with cardiac surgery may also influence the luminal narrowing of trachea. Nevertheless, we performed surgical treatment with staged manner because preoperative expected CPB duration would 
be long and the patient had long-segment CTS with CHD. But concomitant repair of CTS and CHD should be considered as alternative method. RUL atelectasis could have occurred due to incorrect positioning of ETT and accumulation of secretions. When dealing with a patient with CTS during the perioperative period, one should keep in mind that a serious deterioration of the stenotic airway may occur, even if the stenotic lesion had not been severe enough to be treated in the preoperative period. Also, special attention should be paid to the position of the ETT using chest x-ray or fiberoptic bronchoscopy, especially if the patient has CTS associated with tracheal bronchus.

In summary, CTS with CHD can complicate the routine care of infants in the operating room and the ICU. Infants with significant obstructive airway symptoms require urgent attention. Early recognition and prompt diagnosis of acute airway obstruction may prevent complications associated with airway anomalies. Further, it is very important to select an appropriate surgical procedure and optimal timing for the treatment of CTS associated with CHD.

\section{Acknowledgements}

This work was supported by clinical research grant from Pusan National University Hospital 2010.

\section{References}

1. Walker LK, Wetzel RC, Haller JA Jr. Extracorporeal membrane oxygenation for perioperative support during congenital tracheal stenosis repair. Anesth Analg 1992; 75: 825-9.

2. Idriss FS, DeLeon SY, Ilbawi MN, Gerson CR, Tucker GF, Holinger L. Tracheoplasty with pericardial patch for extensive tracheal stenosis in infants and children. J Thorac Cardiovasc Surg 1984; 88: 527-36.

3. Pfammatter JP, Casaulta C, Pavlovic M, Berdat PA, Frey U, Carrel T. Important excess morbidity due to upper airway anomalies in the perioperative course in infant cardiac surgery. Ann Thorac Surg
2006; 81: 1008-12.

4. Chen SJ, Lee WJ, Wang JK, Wu MH, Chang CI, Liu KL, et al. Usefulness of three-dimensional electron beam computed tomography for evaluating tracheobronchial anomalies in children with congenital heart disease. Am J Cardiol 2003; 92: 483-6.

5. Okamoto T, Nishijima E, Maruo A, Yokoi A, Takamizawa S, Satoh $S$, et al. Congenital tracheal stenosis: the prognostic significance of associated cardiovascular anomalies and the optimal timing of surgical treatment. J Pediatr Surg 2009; 44: 325-8.

6. O'Sullivan BP, Frassica JJ, Rayder SM. Tracheal bronchus: A cause of prolonged atelectasis in intubated children. Chest 1998; 113: 53740.

7. Yahagi N, Kumon K, Watanabe Y, Tanigami H, Haruna M, Hayashi $\mathrm{H}$, et al. Detection of tracheal stenosis by cineangiocardiography in infants with congenital heart disease. Anesth Analg 1997; 85: 1180-1.

8. Chiu PP, Kim PC. Prognostic factors in the surgical treatment of congenital tracheal stenosis: a multicenter analysis of the literature. J Pediatr Surg 2006; 41: 221-5.

9. Lee SL, Cheung YF, Leung MP, Ng YK, Tsoi NS. Airway obstruction in children with congenital heart disease: Assessment by flexible bronchoscopy. Pediatr Pulmonol 2002; 34: 304-11.

10. Yang JH, Jun TG, Sung K, Choi JH, Lee YT, Park PW. Repair of longsegment congenital tracheal stenosis. J Korean Med Sci 2007; 22: 491-6.

11. Anton-Pacheco JL, Cano I, Comas J, Galletti L, Polo L, Garcia A, et al. Management of congenital tracheal stenosis in infancy. Eur J Cardiothorac Surg 2006; 29: 991-6.

12. Loukanov T, Sebening C, Springer W, Ulmer H, Hagl S. Simultaneous management of congenital tracheal stenosis and cardiac anomalies in infants. J Thorac Cardiovasc Surg 2005; 130: 1537-41.

13. Yamaguchi M, Ohashi H, Hosokawa Y, Oshima Y, Tsugawa C, Kimura K. Surgical treatment of airway obstruction associated with congenital heart disease in infants and small children. Eur J Cardiothorac Surg 1991; 5: 479-85.

14. Critchley LA, Ho AM, Lee SY. Right upper lobe collapse secondary to an anomalous bronchus after endotracheal intubation for routine surgery. Anaesth Intensive Care 2007; 35: 274-7.

15. Ikeno S, Mitsuhata H, Saito K, Hirabayashi Y, Akazawa S, Kasuda H, et al. Airway management for patients with a tracheal bronchus. $\mathrm{Br}$ J Anaesth 1996; 76: 573-5. 